\title{
EXTRAÇÃo DE CLORETOS EM CASCALHO DE PETRÓlEO UTILIZANDO MICROEMULSÕES
}

\author{
P.H.A.VALENÇA ${ }^{1}$, C.N.CARVALHO ${ }^{1}$, T.N.C.DANTAS ${ }^{2}$ e K.R.O.MELO ${ }^{2}$ \\ ${ }^{1}$ Universidade Federal do Rio Grande do Norte, Departamento de Engenharia Química \\ ${ }^{2}$ Universidade Federal do Rio Grande do Norte, Departamento de Química \\ E-mail para contato: amorimpedro91@gmail.com
}

\begin{abstract}
RESUMO - O cascalho é gerado na produção de petróleo em grande quantidade e contém diversos contaminantes como sais de metais, resíduos de fluidos de perfuração e petróleo. Dentre os contaminantes de difícil remoção estão os cloretos, dada a sua forma de associação no cascalho. Este trabalho tem como objetivo desenvolver um sistema de microemulsão capaz de remover cloretos do cascalho visando a sua utilização na construção civil. Foram utilizados testes de lixiviação com água e com microemulsão e observou-se que o sistema de microemulsão remove $51 \%$ a mais de Cloretos do que a água. Após a remoção com microemulsão, a água não consegue dissolver mais cloretos, possibilitando a reutilização do cascalho tratado em materiais da indústria de construção civil.
\end{abstract}

\section{INTRODUÇÃO}

O cascalho de perfuração gerado em um campo de exploração de petróleo contém excesso de cloreto em sua composição, Ele é obtido na região de Mossoró-RN. Esse excesso de cloreto inviabiliza o uso desse cascalho tratado para a construção civil. Será, portanto, empregada a técnica de extração sólido-líquido (lixiviação) para retirar esse cloreto em excesso destinar a venda, o cascalho que não possui valor comercial.

A literatura de elaboração de sistemas pseudoternários é vasta. No entanto, o estudo de sistemas microemulsionados aplicados à extração de ânions é recente. NASCIMENTO et al. (2013) conseguiu extrair cátions e ânions de água produzida utilizando um sistema microemulsionado. Já DANTAS et al (2003) usou de sistema microemulsionados para extração de metais pesados de água produzida. A extração de ânions contido em sólidos não possui literatura vasta. O objetivo desse trabalho, portanto, é utilizar um sistema microemulsionado para extração de cloretos contidos em cascalho de petróleo.

\section{METODOLOGIA}

Os estudos desse trabalho foram divididos em três partes: Obtenção dos diagramas pseudoternários, análise do teor inicial de cloreto no cascalho e estudo da extração sólido-líquido utilizando um sistema microemulsionado. 


\subsection{Obtenção do Diagrama Pseudoternário}

A obtenção do diagrama consiste na escolha dos constituintes a serem utilizados (Tensoativo, Cotensoativo, Fase Aquosa e Fase Oleosa) na obtenção das regiões do diagrama pseudoternário. Chama-se diagrama pseudoternário pois dois dos seus componentes (no caso, o tensoativo e o cotensoativo) estão presentes sempre em uma proporção fixa no diagrama.

Os constituintes escolhidos para o diagrama foram: CTAB-16 (Tensoativo), Butanol (Cotensoativo), querosene (Fase Óleo) e água deionizada (Fase Aquosa).

Para obtenção do diagrama pseudoternário, pesava-se 1 g do sistema CTAB-16, Butanol e Querosene, a partir de composições previamente definidas. Iniciava-se a titulação do sistema com água. Quando havia mudança de fase, o sistema era centrifugado e a massa de água aferida na balança.

\subsection{Análise do teor inicial do cloreto no cascalho}

Os tipos de análise escolhidos para esse trabalho foram titulação potenciométrica e titulação por $\mathrm{AgNO}_{3}$, (EMBRAPA, 1997). Ambas as técnicas analisam o teor de cloretos livres no meio, partindo do fato que todo cloreto extraível contido em um sólido insolúvel será solúvel em água.

Titulação pontenciométrica (HARRIS, 2008): inicialmente pesa-se $0,5 \mathrm{~g}$ do cascalho em um erlenmeyer, adiciona-se $100 \mathrm{~mL}$ de água deionizada ultrapura, e coloca-se o sistema em agitação, com aquecimento $\left(70^{\circ} \mathrm{C}\right)$, por 1 hora, resfria-se o sistema e completa-se o volume, com água, para $100 \mathrm{~mL}$ de água e titula-se com $\mathrm{AgNO}_{3}$ 0,01 N uma alíquota, em titulador potenciométrico.

Calcula-se a concentração de cloreto através das equações (1) e (2).

$$
\begin{aligned}
& \text { Cloreto }(\mathrm{mg} / \mathrm{L})=\frac{\mathrm{Vt} * \mathrm{~N} * 35,45 * 1000}{\mathrm{Va}} \\
& \text { Cloreto }(\mathrm{g} / \mathrm{Kg})=\frac{\text { Cloreto }(\mathrm{mg} / \mathrm{L}) * \mathrm{D}}{1000 * \mathrm{Ma}}
\end{aligned}
$$

Titulação por AgNO3: pesa-se $2 \mathrm{~g}$ de cascalho e adiciona-se $10 \mathrm{~g}$ de água deionizada em um erlenmeyer, e coloca-se o sistema em agitação, a temperatura ambiente, por $30 \mathrm{~min}$. Após esse tempo, o extrato é transferido para um tubo de ensaio, o qual é levado para a centrífuga por 5 min à velocidade de $3000 \mathrm{rpm}$. Retira-se, então, uma alíquota de $1 \mathrm{~mL}$ desse extrato, a qual é titulado com $\mathrm{AgNO}_{3} 0,05 \mathrm{~N}$ na presença de $\mathrm{K}_{2} \mathrm{Cr}_{2} \mathrm{O}_{4}$ como indicador. Adiciona-se nitrato de prata até que o sistema adquira coloração vermelha tijolo. Deve-se também realizar a titulação do branco com a mesma solução de $\mathrm{AgNO}_{3}$ e indicador. A concentração de cloreto é então calculada pela equação (3).

$$
\text { Cloreto }(\mathrm{g} / \mathrm{Kg})=\frac{(\mathrm{Vs}-\mathrm{Vb}) * 5 * 35,45}{100 * 9 * 2}
$$




\subsection{Estudo da extração de cloreto utilizando microemulsão}

O teor de cloreto será calculado a partir da equação 3. Com esse resultado, será possível comparar a capacidade extrativa entre a água e o sistema microemulsionado, utilizando a equação (4).

\section{RESULTADOS E DISCUSSÕES}

Capacidade de extração $(\%)=(\mathrm{Mm} / \mathrm{Ma}-1) * 100 \%$

\subsection{Diagramas ternário}

Com todos os experimentos realizados, foi possível obter os diagramas pseudoternários, representados na Figura 1.

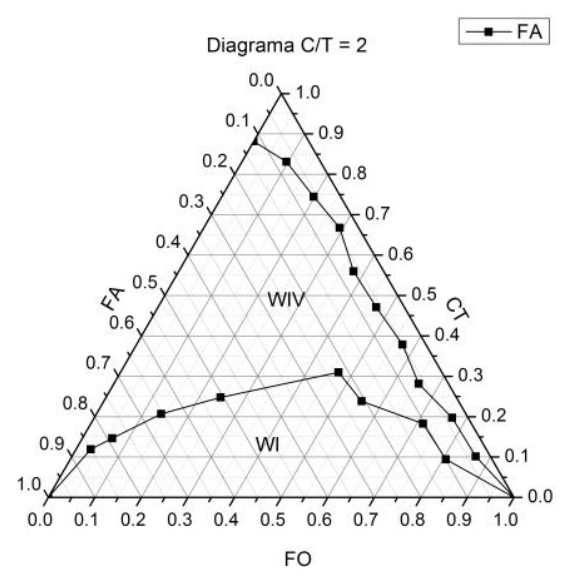

a)

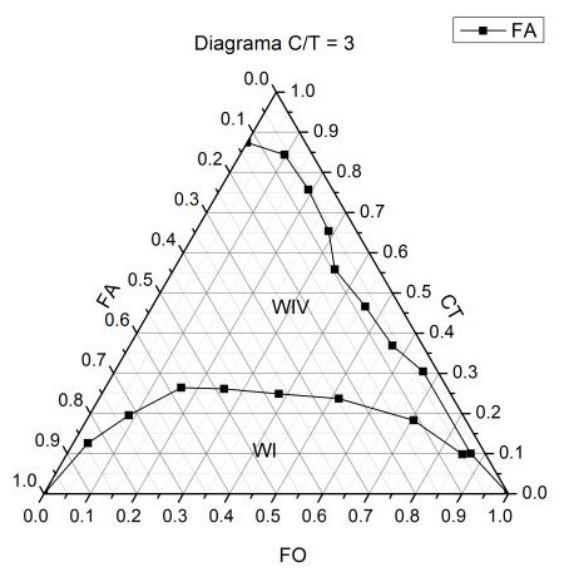

b)

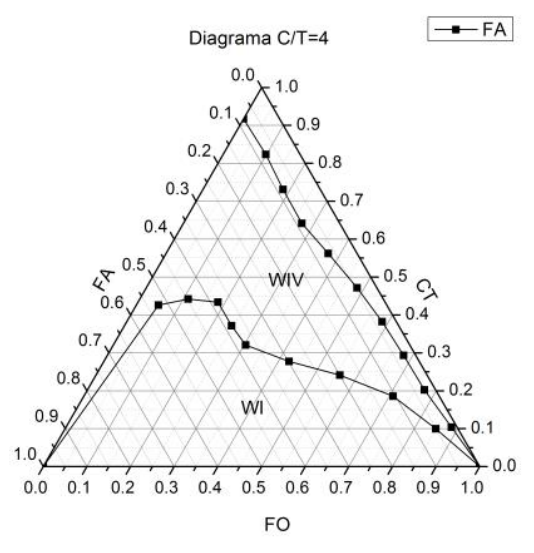

c) 
Figura 1: Diagramas pseudoternários do sistema CTAB 16, Butanol, Querosene e Água deionizada, nas razões (a) $\mathrm{C} / \mathrm{T}=2$, (b) $\mathrm{C} / \mathrm{T}=3$ e (c) $\mathrm{C} / \mathrm{T}=4$

Na Figura 1, é possível observar uma diminuição da região de Winsor IV (microemulsão), na medida em que se aumenta a quantidade de cotensoativo em relação a de tensoativo. Portanto, após a analisar os três diagramas, escolheu-se o diagrama $\mathrm{C} / \mathrm{T}=2$ (Figura 1. a), pois esse apresentou uma maior região de Winsor IV.

\subsection{Análise do teor inicial de cloretos livres no cascalho}

A Tabela 1 apresenta os valores de cloretos livres no cascalho bruto, obtidos por titulometria potenciométrica.

Tabela 1 - Teor de cloretos livres (em g de cloreto/kg de cascalho) a partir da titulometria potenciométrica

\begin{tabular}{|l|c|}
\cline { 2 - 2 } \multicolumn{1}{c|}{} & Teor de cloreto $(\mathrm{g} / \mathrm{kg})$ \\
\hline Amostra 1 & 14,25 \\
\hline Amostra 2 & 15,31 \\
\hline Amostra 3 & 14,25 \\
\hline Média & 14,60 \\
\hline Desvio padrão & 0,61 \\
\hline
\end{tabular}

Os resultados da titulometria por $\mathrm{AgNO}_{3}$ foram calculados de acordo com a equação 2 e podem ser encontrados na Tabela 2.

Tabela 2 - Teor de cloretos livres (em g de cloreto/kg de cascalho) a partir da titulometria com $\mathrm{AgNO}_{3}$

\begin{tabular}{|l|c|c|}
\hline \multicolumn{1}{|c|}{} & Teor de cloreto $(\mathrm{g} / \mathrm{kg})$ & Vol. do branco $(\mathrm{mL})$ \\
\hline Amostra 1 & 14,76 & 0,50 \\
\hline Amostra 2 & 14,76 & 0,50 \\
\hline Amostra 3 & 14,76 & 0,50 \\
\hline Média & 14,76 & 0,50 \\
\hline Desvio padrão & 0,00 & 0,00 \\
\hline
\end{tabular}

Após a análise comparativa dos dois métodos de análises utilizados, pode-se afirmar que os teores de cloretos livres encontrados e apresentados nas Tabelas 1 e 2 , não diferem muito um do outro, apesar das diferentes condições de temperatura empregadas no experimento. Esse fato leva a conclusão que a temperatura empregada durante a extração sólido-líquido será um parâmetro que não influenciará de forma significativa o processo.

Assim, de acordo com os resultados e a proximidade encontrada entre os dois métodos, os 
baixos desvios padrões experimentais, é possível concluir que o teor inicial de cloretos livres gira em torno de $14,68 \pm 0,08 \mathrm{~g} / \mathrm{kg}$ (média entre os dois resultados).

\subsection{Extração de cloretos utilizando microemulsões}

Com a escolha do diagrama pseudoternário e com o teor inicial de cloretos livres no meio determinados, os resultados da lixiviação utilizando o sistema microemulsionado proposto foram obtidos. Os pontos escolhidos no diagrama da Figura 1.a, foram baseados na rede de Scheffé (SCHEFFÉ, 1999). Este diagrama consiste em um triângulo equilátero, o qual contém 7 pontos igualmente espaçados. A partir desse diagrama, é possível analisar a influência dos constituintes da microemulsão perante a extração. Os pontos escolhidos podem ser encontrados na Tabela 3, enquanto o diagrama de Scheffé (1999), na Figura 2.

Tabela 3 - Composições, em fração mássica, dos pontos de microemulsão escolhidos no diagrama de Scheffé

\begin{tabular}{|c|c|c|c|}
\hline Pontos & Razão C/T & Querosene & Água deionizada \\
\hline 1 & 25,00 & 5,00 & 70,00 \\
\hline 2 & 32,50 & 5,00 & 62,50 \\
\hline 3 & 40,00 & 5,00 & 55,00 \\
\hline 4 & 32,50 & 12,50 & 55,00 \\
\hline 5 & 25,00 & 20,00 & 55,00 \\
\hline 6 & 25,00 & 12,50 & 62,50 \\
\hline 7 & 32,50 & 8,75 & 58,75 \\
\hline
\end{tabular}

Após a realização dos extrações com os pontos de microemulsão escolhidos, os resultados obtidos podem ser observados no gráfico de colunas da Figura 3. 


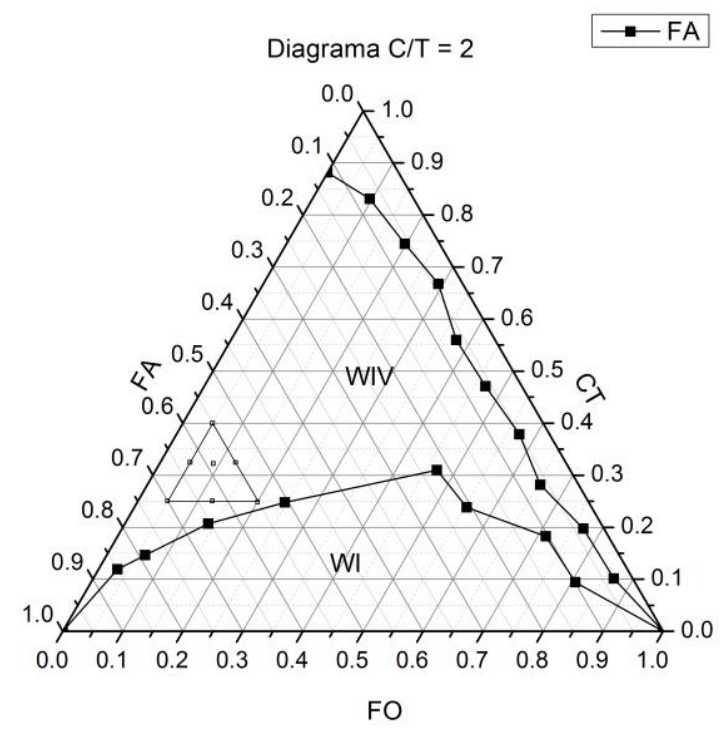

Figura 2- Localização do Diagrama de Scheffé no diagrama pseudoternário escolhido.

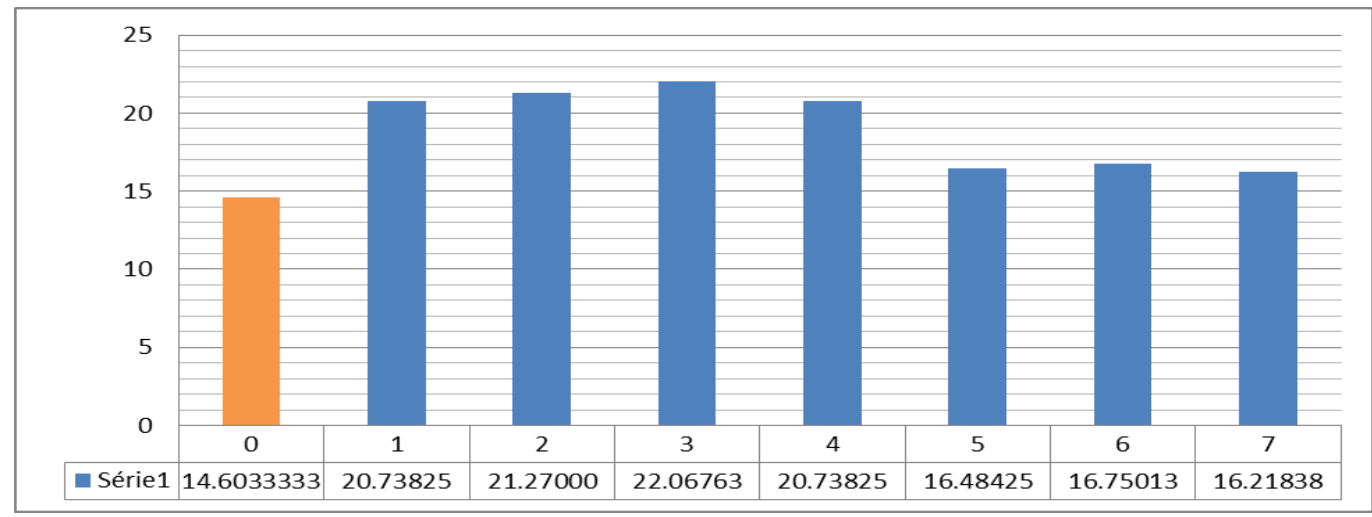

Figura 3 - Resultados da lixiviação (em g de cloreto/kg de cascalho), sendo o ponto 0 o valor do teor de cloreto livre pela lixiviação feita somente com água a temperatura ambiente (titulometria por $\mathrm{AgNO}_{3}$ ). Os valores abaixo das barras são o teor de cloreto no meio (em g de cloreto/kg de cascalho).

Como era esperado, o poder de extração da microemulsão é maior que o da água deionizada. A partir da Figura 3 e da Tabela 4, observa-se que os primeiros pontos que contêm maior teor de água (pontos 1, 2 e 3) e o ponto que contém maior razão C/T (ponto 4) foram os que forneceram melhor resultado de extração.

Por fim, a capacidade de extração do sistema microemulsionado foi calculada conforme a equação (4) e pode ser vista na Tabela 4 
Tabela 4 - Capacidade, em porcentagem, de extração dos Sistemas microemulsionados

\begin{tabular}{|l|c|c|c|c|}
\hline Pontos & $\begin{array}{r}\text { Capacidade de } \\
\text { extração - Tit. } \\
\text { Potenciométrica }\end{array}$ & $\begin{array}{c}\text { Capacidade de } \\
\text { extração - Tit. } \\
\text { por AgNO }\end{array}$ & Média & Desvio Padrão \\
\hline 1 & 42,01 & 40,54 & 41,28 & 1,04 \\
\hline 2 & 45,65 & 44,14 & 44,90 & 1,07 \\
\hline 3 & 51,11 & 49,55 & 50,33 & 1,11 \\
\hline 4 & 42,01 & 40,54 & 41,28 & 1,04 \\
\hline 5 & 12,88 & 11,71 & 12,30 & 0,83 \\
\hline 6 & 14,70 & 13,51 & 14,11 & 0,84 \\
\hline 7 & 11,06 & 9,91 & 10,48 & 0,81 \\
\hline
\end{tabular}

\section{CONCLUSÕES}

Após realização deste trabalho e os resultados da extração de cloretos do cascalho utilizando o sistema microemulsionado, é possível concluir que os sistemas microemulsionados apresentam eficiência de extração bem superior a água. E que o ponto ótimo a ser utilizado para a extração sólidolíquido será o ponto 1 devido ele possuir uma maior quantidade de água e uma menor quantidade de tensoativo, cotensoativo e óleo que os demais. $\mathrm{O}$ fato desse ponto 1 usar mais água será sustentado pela busca da maior sustentabilidade do processo, visto que o teor de óleo utilizado nesse ponto é menor que nos demais.

\section{NOMENCLATURAS}

$\mathrm{Vt}=$ Volume gasto de AgNO3

$\mathrm{N}$ = concentração do AgNO3

$\mathrm{Va}=$ Volume da amostra

$\mathrm{D}=$ Diluição inicial da amostra $(100 \mathrm{~mL})$

$\mathrm{Ma}=$ Massa da amostra $(0,5 \mathrm{~g})$

Vs = Volume de $\mathrm{AgNO}_{3}$ gasto na titulação da amostra

$\mathrm{Vb}=$ Volume de $\mathrm{AgNO}_{3}$ gasto na titulação da solução branco.

Mm = Média da extração utilizando microemulsão $(\mathrm{g} / \mathrm{kg})$

Ma = Média da extração utilizando água $(\mathrm{g} / \mathrm{kg})$

\section{REFERÊNCIAS BIBLIOGRÁFICAS}

DANTAS, T. N. C. et al. Heavy metals extraction by microemulsions. Water Research, v. 37, n. 11, p. 2709-2717 2003.

ISSN 0043-1354. Disponível em: http://www.sciencedirect.com/science/article/pii/S0043135403000721 >.

EMPRESA BRASILEIRA DE PESQUISA AGROPECUÁRIA. ANÁLISE DE CLORETOS, 23.5.3: 
Manual de Análise de Solos. 2 ed. Rio de Janeiro: Embrapa, 1997.

HARRIS, D. C., Análise Química Quantitativa, 7a ed., LTC - Livros Técnicos e Científicos Editora, 2008.

NAJJAR, Reza. Microemulsions: An Introduction to Properties and Applications. Croácia: Intech, 2012.

NASCIMENTO et al. Análise da Influência do pH e da Concentração de Matéria Ativa na Extração de Ânions em Água Produzida Sintética Utilizando Sistemas Microemulsionados. Anais do $7^{\circ}$ Congresso Brasileiro de Pesquisa e Desenvolvimento em Petróleo e Gás. Aracaju: ABPG, 2013.

SCHEFFÉ, Henry. The Analysis of Variance. Berkeley, CA - USA: John Wiley \& Sons, 1999. 477 p 